\title{
ENZYME ACTIVATION USING DYNAMIC MANIPULATION OF PROCESS VARIABLES
}

João Henrique Dantas ${ }^{1 *}$, Matheus Lopes Harth ${ }^{1}$, Leandro Daniel De Paris ${ }^{1}$, André D. D. Cavalcanti ${ }^{1,2}$, Pedro Augusto Arroyo ${ }^{1}$, Maria Isabel Rodrigues ${ }^{2}$, Flavio Faria Moraes ${ }^{1}$, Gisella Maria Zanin ${ }^{1}$

1.Chemical Engineering Department, State University of Maringá, Av. Colombo 5790, BI. D-90, Maringá-PR, Brazil

2. Food Engineering Department, Faculty of Food Engineering, State University of Campinas, Av. Barão Gerald $\mathrm{s} / \mathrm{n}$. Campinas- SP, Brazil

${ }^{*}$ Corresponding author: J.H. Dantas (Fax: +55 44 30114771; e-mail:

ikedantas@yahoo.com.br)

\section{ABSTRACT}

Experimental design and surface response methodology were used to study the production of radish oil ethyl ester, using Burkholderia cepacia lipase. The estimative of the standard effects were determined as a function of time to analyze the importance of some variables. The results showed the importance of variables, as well the extents of their effect, vary throughout the reaction. Then was possible to analyze the behavior of the reaction medium and to propose situations where higher yields could be obtained. In fact, when the reactor was operated in this way, an $80,1 \%$ yield was achieved, much higher than common operation (39.9\%). Also, enzymatic activity of ester production was tenfold.

Indexing terms/Keywords:- Experimental design; radish oil; Burkholderia cepacia lipase; standard effects as a function of time; dynamic manipulation;Enzyme activation; ethyl ester.

\section{Academic Discipline And Sub-Disciplines}

Biochemical process; Enzyme Technology; kinetics

\section{SUBJECT CLASSIFICATION}

Chemical Engeneering; Chemical, Biochemical

\section{TYPE (METHOD/APPROACH)}

Experimental; Statistic aplication

\section{Council for Innovative Research}

\section{Peer Review Research Publishing System}

\section{Journal: JOURNAL OF ADVANCES IN BIOTECHNOLOGY}

Vol .5, No. 1

www.cirjbt.com ,jbteditor@gmail.com 


\section{INTRODUCTION}

Experimental design and modeling by response surfaces make a collection of statistical techniques and useful mathematics tools for developing, improving and optimizing new processes. In this approach, the response of interest is influenced by a number of process variables and its objective is to optimize this response, always seeking the individual effects of each independent variable, or the combination of their effects, contribute to this goal, that is, to increase the production of the desired product [1-3]. Additionally, by means of a mathematical model, one gains the ability to quantify the influence that each variable has on the system, which allows classifying the significance of variables involved.

Recent works show the variables preferentially studied on the production of vegetable oil esters are temperature, relative amount of biocatalyst, molar ratio of reagents, $\mathrm{pH}$ and reaction time. The main goal of including the latter variable in the experimental design is to reduce the reaction time seeking to maintain the response variable optimized, as shown in several studies in the literature [4-9]. Usually, these studies conclude that maximal response occurs at the highest level studied [10-13]. Additionally, it was verified that the process is not always controlled by the same variables, even for similar studies with similar levels [9,14-17].

Understanding the biochemical processes in order to increase efficiency is an important stage of recent research. Experimental design have aided in this task given that it fits simpler models, which can be limited but are able to describe the phenomenon studied sufficiently. To use a complete phenomenological model that includes temperature, molar ratio and enzyme amount as functions of time would be extremely laborious and require enormous computational effort. Besides, the model response would be inaccurate due the large amount of parameters required by model $[1,13]$.

This study will investigate the estimate of the standard effects as functions of time and factors of analysis to describe the importance of each variable throughout the reaction. Therefore, this work seeks to unravel the intrinsic dynamics of the reaction. After that, the variables will be manipulated throughout the ester production process according to their importance obtained previously.

Thus, we establish as our challenge to determine which variables, as well their period of importance, are influencing the production of ester and what actions should be taken in order to increase the yield of the desired product by optimizing beneficial effects and minimizing the deleterious ones on the reaction between the radish oil and ethanol in an solvent-free medium.

\subsection{Factorial design and enzymatic reactions}

In previous works on production of ethyl esters in which the independent variables temperature, molar ratio of alcohol and oil and the relative amount of lipase were studied, it was observed that an experimental design based on the end of the reaction enables justifying the results with concepts already established in the study of enzymatic reactions. For example, if there is a high concentration of a reactant, it will exist the effect of displacement of chemical equilibrium to product formation and possible inhibition of the catalyst by substrate excess, or even breakdown of the enzyme by a destabilizing effect at the active site caused by the high amount of alcohol, and then experimental designs would indicate the variable molar ratio as an important variable in the process [14,18-21,23]

The temperature would also be considered important in the production of ester since its increase would promote a greater number of collisions between the reactant molecules, a possible denaturation of the enzyme and a reduction of the stability of the emulsion [7, 16,18,19,22-24]. The authors Coteron, A. et al. [25], Kristensen, J.B. et al. [15] and Paroul, N. et al. [16], claim that temperature has three important roles in this type of reaction. The first is the decrease of viscosity with increasing temperature of the reaction mean, which provides better miscibility and reduced diffusional limitations. The second role is the influence on the condition of optimum temperature of the enzyme $[15,16,25]$. Finally, the third role is increased cavitation that influences emulsion formation $[26,27]$.

Additionally, the amount of enzyme in the reaction medium may also be important, since higher amounts of this enzyme, reactions occur more rapidly and equilibrium will be reached sooner. However, a high enzyme concentration could facilitate the formation of agglomerates which hinder the access of substrate to the enzymatic active site and lead to lower reaction rates $[4,17,19,23,28]$. Then, the three variables discussed previously will be significant for the experimental design $[4,16,17,19,23,29]$.

\section{MATERIALS AND METHODS}

\subsection{Lipase}

Amano P.S. lipases from Burkholderia cepacia was used in its free form. The transesterification activity was measured by 2-phenethyl acetate production giving $2023.68 \pm 209.09 \mathrm{U} / \mathrm{g}$ of protein. The hydrolytic activity of olive oil was $1865.60 \pm$ $89.23 \mathrm{U} / \mathrm{g}$ of protein [30].

\subsection{Reagents}

Amano lipase PS, from Burkholderia cepacia, 2-phenethyl alcohol, vinyl acetate, 2-phenethyl acetate, and diisopropyl ether were purchased from Sigma-Aldrich Chemical Co., St. Louis, MO, USA. Absolute ethanol 99.9\% was from Cinética, Brazil. Non refined radish oil was provided by the Agronomic Institute of Paraná - IAPAR - Londrina. The reagents used in high performance liquid chromatography (HPLC) were $n$-hexane, n-propyl alcohol and acetonitrile (J.T. Baker). The 
standards tri-olein, di-olein, mono-olein and methyl-oleate were purchased from Accustandard. Other materials and reagents were of analytical grade.

\subsection{Experimental design}

The effects of process parameters in the enzymatic transesterification reaction were studied using a multifactorial design of experiments $2^{3}$ with four replicates at the center point. Twelve experiments were performed in a random order. The levels of each independent variable were chosen based on the importance of the experiments. The parameters were temperature (X1), molar ratio alcohol/oil (X2) and relative amount of enzyme (X3). The coded, corresponding uncoded and yield values as a function of time are given in Table 1. The ester yield of the reaction was taken as response of the design experiment. Results were analyzed using Statistica version 7.0 (StatSoft Inc., USA) software. The statistical significance of the regression coefficients was determined by Student's test, and the proportion of variance explained by the model obtained was given by the multiple coefficient of determination, $R^{2}$ [29].

\subsection{Transesterification reaction}

The reactions of ethyl esters synthesis were performed in a jacketed cylindrical batch reactor $(6 \mathrm{~cm}$ high and $4 \mathrm{~cm}$ of inner diameter) with a capacity of $50 \mathrm{~mL}$. The reaction was performed for $72 \mathrm{~h}$ with samples taken at predetermined times (shown at Table 1). Ethanol was added in three stages (equal amounts at the beginning, after $12 \mathrm{~h}$, and after $24 \mathrm{~h}$ ). Production of ethyl esters were monitored by HPLC. The enzymatic activity of ester production was defined as the amount of protein required to produce a micromole of ester in a minute [30]. A combined linear gradient with aqueous/organic and non-aqueous phases, adapted from Holcapek, M. et al. [31] was used for HPLC [30,31]

\subsubsection{Ester production using non-static variables}

For the experiment using non-static variables, the latter were adjusted at the minimal level of planning design, therefore $40^{\circ} \mathrm{C}, 5 \%(\mathrm{w} / \mathrm{w})$ amount of enzyme an alcohol: oil molar ratio $6: 1$. Throughout the reaction, the variables were manipulated proportionally to a linear regression of the estimative of the standard effects as a function of time. The conditions of variables are described in Table 2.

\subsection{Determination of transesterification activity by 2-phenethyl acetate production}

Transesterification activity in the reaction of 2-phenethyl acetate formation using 2-phenethyl alcohol and vinyl acetate was measured by high performance liquid chromatography (HPLC, Varian 920-LC) with ODS-C18 column and UV-VIS detector at $254 \mathrm{~nm}$, using acetonitrile and water (42:58) as mobile phase, room temperature, $30^{\circ} \mathrm{C}$, injection of $10 \mu \mathrm{L}$, and flow rate of $1.0 \mathrm{~mL} \mathrm{~min}-1$. The reaction mixture was prepared by adding $0.6 \mathrm{~mL}$ of 2-phenethyl alcohol and $2.4 \mathrm{~mL}$ of viny acetate to $20 \mathrm{mg}$ of the biocatalyst and kept under stirring for $20 \mathrm{~min}$ at $37^{\circ} \mathrm{C}$. The method of transesterification activity by 2-phenethyl acetate production was proposed by the supplier Amano P.S. as assay method of transesterification activity.

\subsection{Calculations}

Yield of product formation (Yi) were determined by Equation 1.

$$
Y_{i}=\frac{\text { moles of product if formed }}{\text { moles of product ithat can be formed }}
$$

\section{RESULTS AND DISCUSSION}

\subsection{Ester production using static variables}

Table 1 shows the coded and uncoded variables, the yield of the samples and the order in which the experiments were performed. The yield against time and the enzymatic activity of Burkholderia cepacia lipase in ester reaction production in static condition was depicted in Figure 1a and Figure 1b, respectively. 
Table 1: The coded, corresponding uncoded variables and yield values as a function of time

\begin{tabular}{|c|c|c|c|c|c|c|c|c|c|c|c|c|c|c|c|c|}
\hline & & Variables & & & & & & Ester & r Yield ( & $(\%)-\operatorname{Re}$ & eaction t & ime (min & & & & \\
\hline & $\begin{array}{c}\text { Temperature } \\
\left({ }^{\circ} \mathrm{C}\right)\end{array}$ & $\begin{array}{c}\text { Molar ratio } \\
\text { (alcohol: } \\
\text { oil) }\end{array}$ & $\begin{array}{l}\text { Amount of } \\
\text { Lipase (\%) }\end{array}$ & 0 & 30 & 60 & 90 & 120 & 240 & 360 & 480 & 600 & 720 & 1440 & 2880 & 4320 \\
\hline Exp1 & $40^{\circ}(-1)$ & $6: 1(-1)$ & $5(-1)$ & 0,00 & 8,02 & 6,13 & 7,42 & 7,66 & 9,65 & 9,56 & 10,91 & 11,78 & 13,64 & 16,02 & 16,22 & 25,01 \\
\hline Exp2 & $60^{\circ}(1)$ & $6: 1(-1)$ & $5(-1)$ & 0,00 & 6,76 & 5,01 & 6,33 & 7,37 & 10,82 & 12,56 & 14,40 & 15,33 & 16,25 & 18,91 & 19,80 & 30,69 \\
\hline Exp3 & $40^{\circ}(-1)$ & 12:1 (1) & $5(-1)$ & 0,00 & 2,79 & 3,93 & 2,49 & 1,92 & 4,38 & 5,74 & 6,19 & 8,64 & 10,90 & 12,89 & 18,70 & 25,88 \\
\hline Exp4 & $60^{\circ}(1)$ & 12:1 (1) & $5(-1)$ & 0,00 & 1,36 & 2,27 & 2,35 & 2,31 & 4,80 & 6,35 & 7,96 & 9,44 & 10,67 & 13,91 & 18,18 & 22,45 \\
\hline Exp5 & $40^{\circ}(-1)$ & $6: 1(-1)$ & $10(1)$ & 0,00 & 6,13 & 5,94 & 7,54 & 12,38 & 12,39 & 13,45 & 13,91 & 15,60 & 15,59 & 18,64 & 20,56 & 20,63 \\
\hline Exp6 & $60^{\circ}(1)$ & $6: 1(-1)$ & $10(1)$ & 0,00 & 7,60 & 8,59 & 10,45 & 11,87 & 14,90 & 16,53 & 18,27 & 19,14 & 19,96 & 29,75 & 36,36 & 34,23 \\
\hline Exp7 & $40^{\circ}(-1)$ & 12:1 (1) & $10(1)$ & 0,00 & 4,82 & 2,36 & 3,65 & 4,93 & 9,12 & 8,92 & 10,82 & 12,77 & 13,17 & 16,94 & 21,59 & 28,58 \\
\hline Exp8 & $60^{\circ}(1)$ & 12:1 (1) & $10(1)$ & 0,00 & 2,61 & 4,38 & 5,26 & 6,18 & 10,62 & 13,03 & 15,32 & 16,71 & 18,23 & 23,21 & 33,20 & 39,98 \\
\hline Exp9 & $50^{\circ}(0)$ & $9: 1(0)$ & $7,5(0)$ & 0,00 & 5,90 & 3,11 & 5,45 & 7,47 & 10,17 & 11,98 & 13,77 & 14,07 & 14,40 & 19,46 & 23,07 & 26,40 \\
\hline Exp10 & $50^{\circ}(0)$ & $9: 1(0)$ & $7,5(0)$ & 0,00 & 6,03 & 5,87 & 5,88 & 5,89 & 10,67 & 11,86 & 12,90 & 14,42 & 16,06 & 17,82 & 23,12 & 24,69 \\
\hline Exp 11 & $50^{\circ}(0)$ & 9:1 (0) & $7,5(0)$ & 0,00 & 2,75 & 4,65 & 5,53 & 6,37 & 10,68 & 12,22 & 13,76 & 14,93 & 16,12 & 19,06 & 28,71 & 32,11 \\
\hline Exp 12 & $50^{\circ}(0)$ & $9: 1(0)$ & $7,5(0)$ & 0,00 & 4,90 & 4,54 & 5,62 & 6,58 & 10,51 & 12,02 & 13,48 & 14,47 & 15,52 & 18,78 & 24,97 & 27,73 \\
\hline
\end{tabular}

In the first 500 minutes of reaction there is a rapid accumulation of esters, as can be seen in Figure $1 \mathrm{a}$. However, the rate of production reduces along the course of the reaction, while ester concentration keeps increasing. The decrease in reaction rate is caused by the reduction of reagents concentrations and by deleterious effects such as inhibition and destabilization of the active site of the enzyme, which are, always, more prominent in intermediate and final periods of biochemical reactions than in the early stages [32].

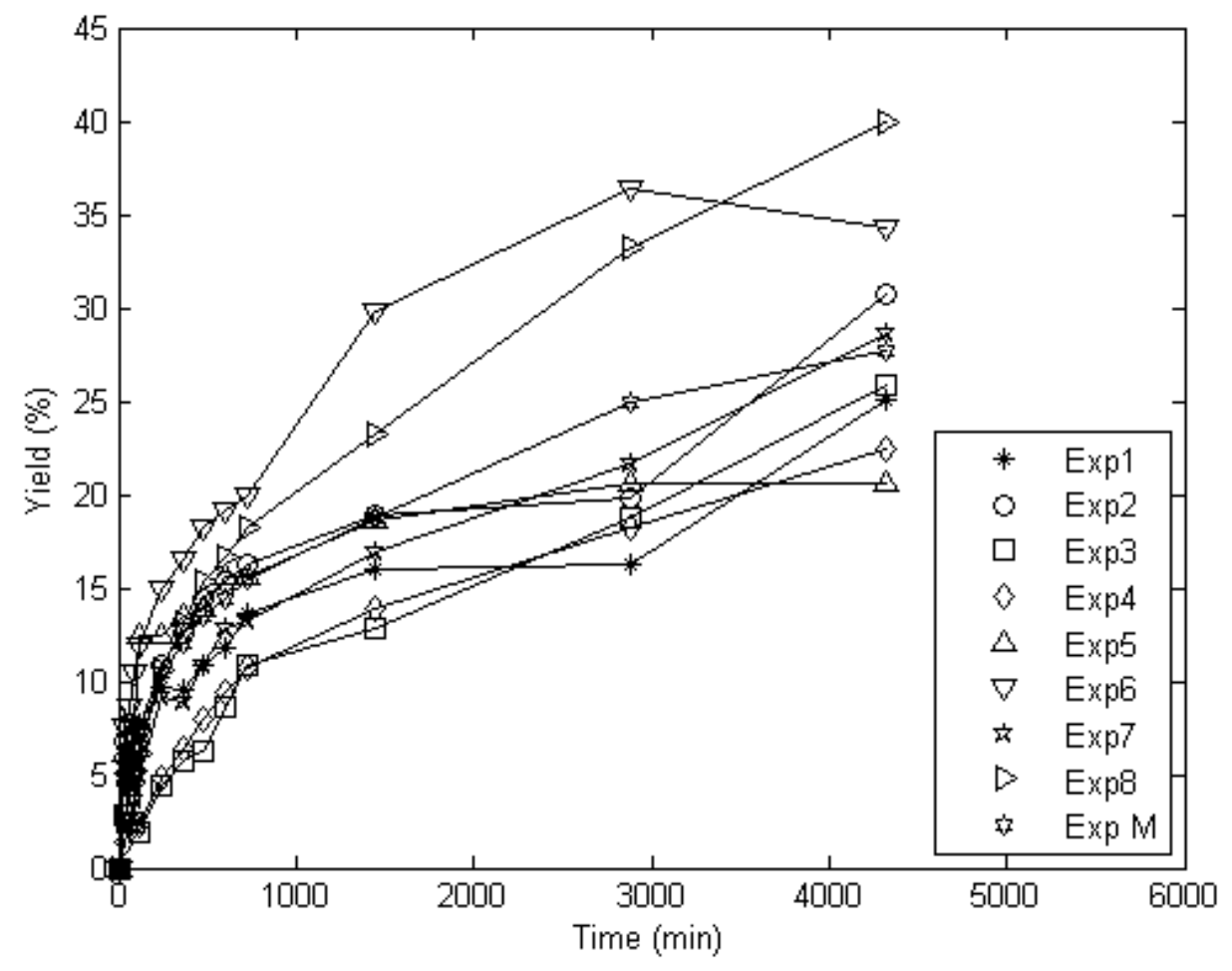

Fig 1a: Ester yield as a function of the time and experiments of planning design. 


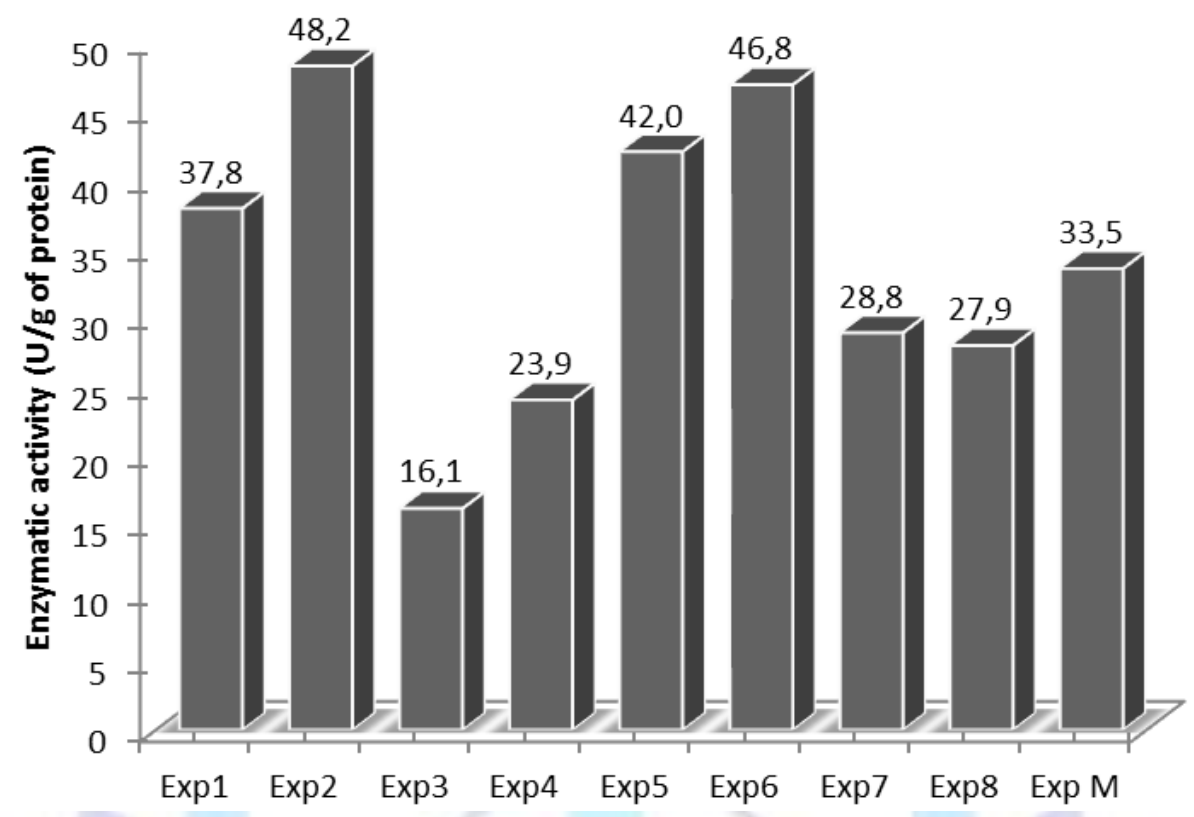

Fig 1b: Enzymatic activity of Burkholderia cepacia lipase in ester reaction production in static condition

Processes that use cosolvents in the reaction media often have higher yields [32]. But using them in ester production is discouraged, because a subsequent step for removing such component is required, increasing the difficulty for purification of esters [33]. Additionally, organic solvents increase the toxicity of the reaction media, requiring more control and safety measures for the industrial plant that produces esters. Moreover, cosolvents are derived from petroleum and their use frustrates the independence of the renewable biofuel technology $[16,34,35]$.

\subsection{Experimental design and estimates of the effects of variables as a function of time}

The estimates of the effects of variables as a function of time are shown in Figure 2, although similar to a Pareto diagram, the data of the diagram are shown as a function of time. Inside the region defined by the dash-dot lines, which represent the $95 \%$ confidence interval, the effects are statistically not significant. Therefore, the significant effects for the process have values, in modulus, that are greater than the dash-dot lines. These effects with $95 \%$ confidence reject the null hypothesis and indicate an influence on the process within studied levels.

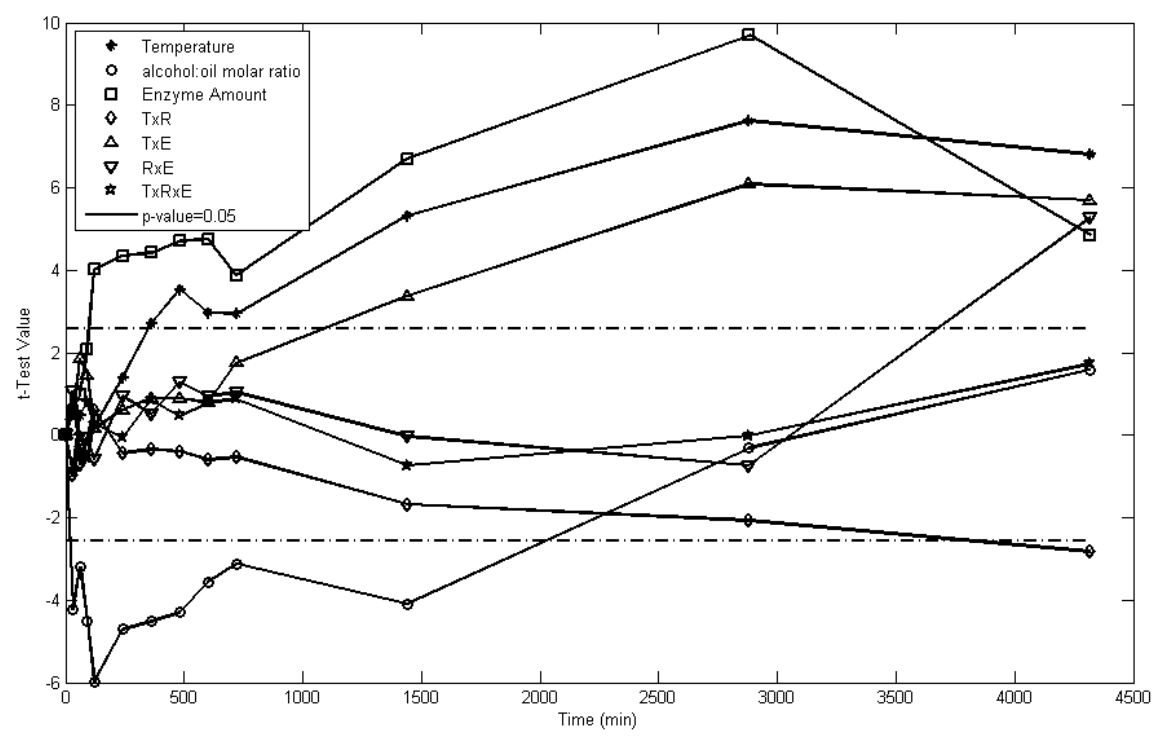

Fig 2: Estimative of the standard effects as a function of time. The codes (1x3) represents the interaction of variables temperature and amount of enzyme; (2x3) represents alcohol/oil molar ratio and amount of enzyme and (1x2) represents temperature and alcohol/oil molar. 
From Figure 2, it was still possible to verify how the variables or their interactions influence the process. When the estimative of the standard effect is positive, it indicates an increase in the response variable, in this case, a higher ester yield. However, if the value is negative, the process is suffering a detrimental effect, causing, in this work, a lower ester yield.

\subsubsection{Influence of temperature variable in the yield of the reaction}

It is not possible to assert that the temperature exerts influence on the yield before 360 minutes because, in this period, the estimates of the effects of variables were inside the region defined by the dash-dot lines. Then if the levels studied are changed from highest to lowest value is not possible to conclude about the effect on yield, only a tendency of increase can be verified. After this initial reaction period, $360 \mathrm{~min}$, the magnitude of the temperature effects grows continually and becomes significant. At the point of largest significance $(2880 \mathrm{~min})$ a temperature increase from $40(-1)$ to $60{ }^{\circ} \mathrm{C}(+1)$, provides a gain of $7.65 \%$ in the yield of ester.

Published articles generally study enzymatic reactions through experimental designs based on the final yield of the reaction and invariably conclude that temperature is the most important variable for the studied system $[7,10,16,23]$. However, this variable trend of influence has a divergent behavior between these studies, even though they used similar temperature ranges. In some studies, temperature increase causes activation of the enzyme, achieving higher yields. Yet, in other works, the same variation shows detrimental effects on the response variable, which the authors indicate that there are caused by thermal inactivation. Thus, these conflicting results do not reveal this variable real influence and possible phenomenological effects involved.

Given the above arguments and the results of this work, it is proposed that the temperature should be increased along the reaction course. Since, at the beginning of the reaction, yield is not strongly influenced by this variable, as can be seen in Figure 2, the temperature values can be kept at lower levels to save energy and avoid possible effects that may harm the enzyme. In the reaction's course, the temperature would be gradually increased until it reaches the maximum value determined as optimal for the used lipase. This dynamic control will allow the lipase to be only subjected to temperatures of maximum activity and deactivation in a shorter time interval, only when it is most needed. Thus, this procedure would reduce thermal inactivation effects on the biocatalyst.

\subsubsection{Influence of alcohol/oil molar ratio variable in the yield of the reaction}

Estimates of effects of the variable alcohol/oil molar ratio have a strong significant negative value since the initial period of the tests (Figure 2). In the first 500 min of reaction, the results indicate a change from the lowest to the highest level of this variable in the range studied, result in an average reduction of $5 \%$ in the reaction yield. In the same period, this variable reaches its maximum significance at $120 \mathrm{~min}$, when the value of the effect is highly negative. After this point, the significance of this variable is continuously reduces until $3200 \mathrm{~min}$, when the effect's sign reverses, having a slightly positive effect thereafter, although not statistically significant, up to the end of the test.

In our work, the fractional addition of alcohol in the reaction was used in order to maintain low the alcohol concentration in the reaction mean and avoid effects of inhibition or inactivation, while providing a stable emulsion formation [21,36]. However, even with the fractional addition, the results indicated that, under conditions of high proportions of alcohol, it was detrimental to the reaction in the early stages. This suggests a constant addition of alcohol proportional to the consumption of reagents would be the best strategy, even if the emulsion formation would be impaired.

The variable amount of lipase shows an opposite behavior to the one showed by the variable alcohol/oil molar ratio, as can be seen in Figure 2. In the early stages of testing, its significance increases until 120 min when it reaches a plateau and its effect value remains constant up to $720 \mathrm{~min}$. After this period, both value and significance of the effect reaches a point of maximum effect with a value of 9.70 , when the variation in levels caused an increase in the yield of $9.70 \%$. But at the end of the reaction the importance and value of the effect decreased considerably.

\subsubsection{Influence of amount of lipase variable in the yield of the reaction}

The amount of lipase in the reaction medium, in most studies, is identified as an important variable in the process $[10,16,23]$ and, in all studies reviewed, the effect of increasing lipase concentration is either an increase in the response variable or a tendency to lower the time for the system to reach equilibrium $[16,37]$. In fact, the greater the relative amount of biocatalyst, the higher is the reaction rate in the same period of time, leading to one of two consequences: either shorter time to reach chemical equilibrium or increased yield, depending on whether the reaction time was sufficient to reach equilibrium. Additionally, very dilute protein solutions are highly prone to inactivation. This is especially true in oligomeric protein solutions, in which dissociation of subunits can occur at low concentration and cause loss or reduction of activity if the latter do not have this function [38].

The results obtained in our study suggest the effects of mass transfer resistance due to higher enzyme concentration were not a significant factor that must be considered when producing ester in an enzymatic reaction media. However, the amount of lipase is an economic factor that may limit or even preclude commercial applicability of the studied system.

\subsubsection{Influence of interaction between the variables in the yield of the reaction}

The interaction between the variables temperature and amount of enzyme (1x3) has shown a significant positive effect starting at $1000 \mathrm{~min}$ of reaction and increasing onwards (Figure 2). The interactions between mole ratio and amount of enzyme (2x3), and temperature and molar ratio (1x2) only become significant in the last sample with the greatest reaction 
time. The interaction $(2 \times 3)$ has effect values close to zero over most of the entire period up to 3000 min and the interaction (1x2) was always negative and growing in module.

The phenomenological effects associated with these interactions are difficult to describe and are rarely mentioned in the literature. Avelar, M.H.M. et al. [18] has shown that, for systems with enzymatic hydrolysis, high concentration of canola oil at low temperatures reduces the yield, attributing this effect to agglomeration of oil particles, which causes instability of the emulsion. This conclusion is valid also to this work and can even be extended to organic systems of organic alcohol and oil, but the interaction between the other variables is difficult to be interpreted or proven.

\subsubsection{Experimental design and modeling by response surfaces}

Table 3 shows the models that fitted well the experimental data. The smallest value of the multiple coefficient of determination $\mathrm{R}^{2}$ was 0.983 , indicating an error of less than $1 \%$. The models generated by the experimental design constitute the most popular technical results for optimization of chemical and biochemical processes.

a)

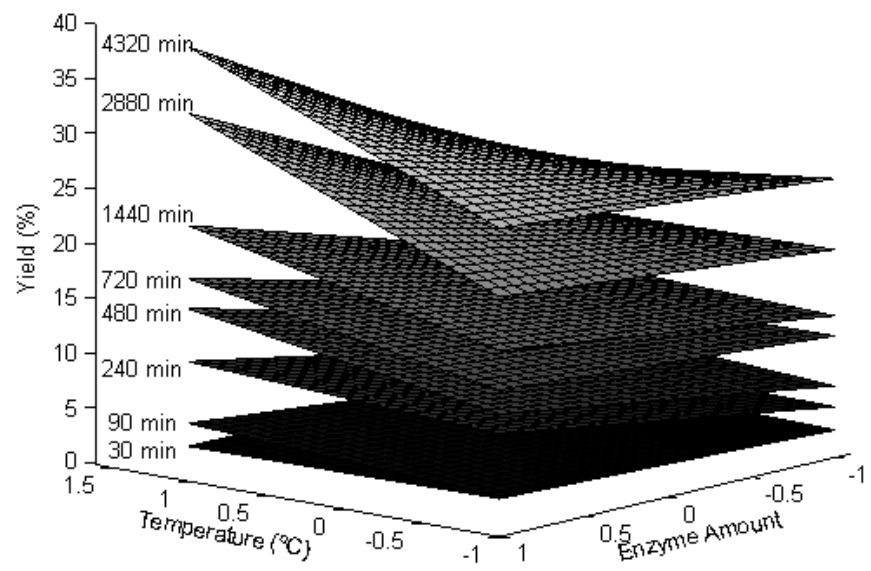

b)
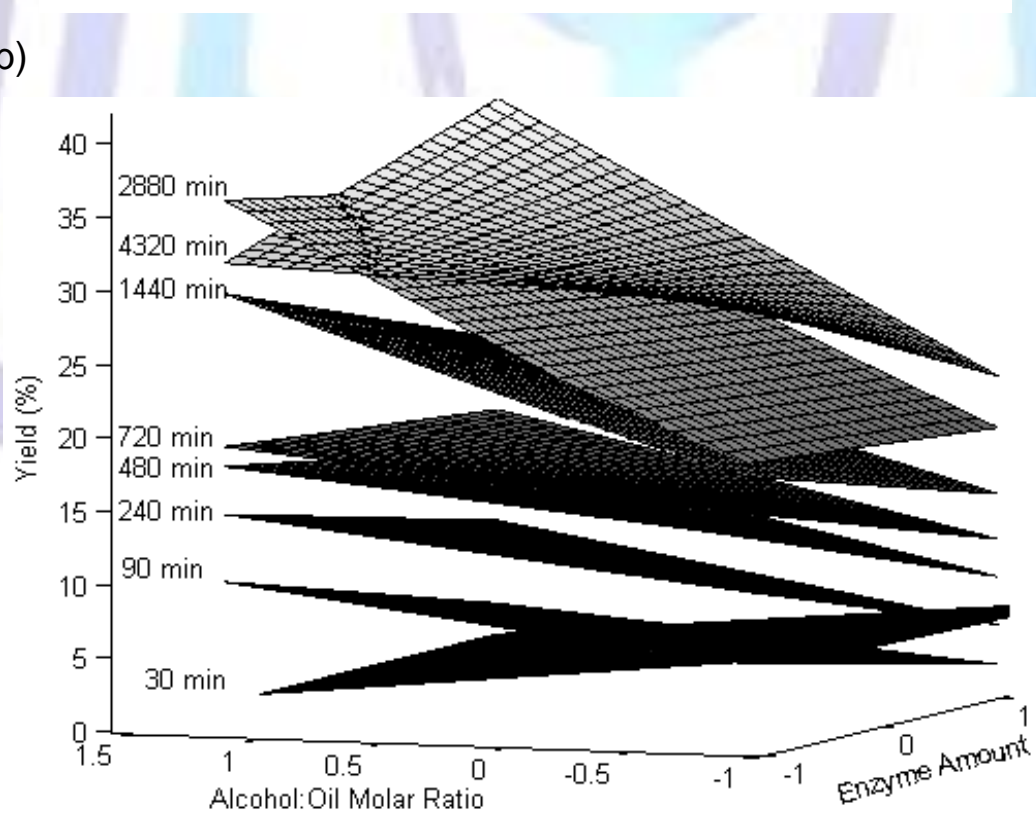
c)

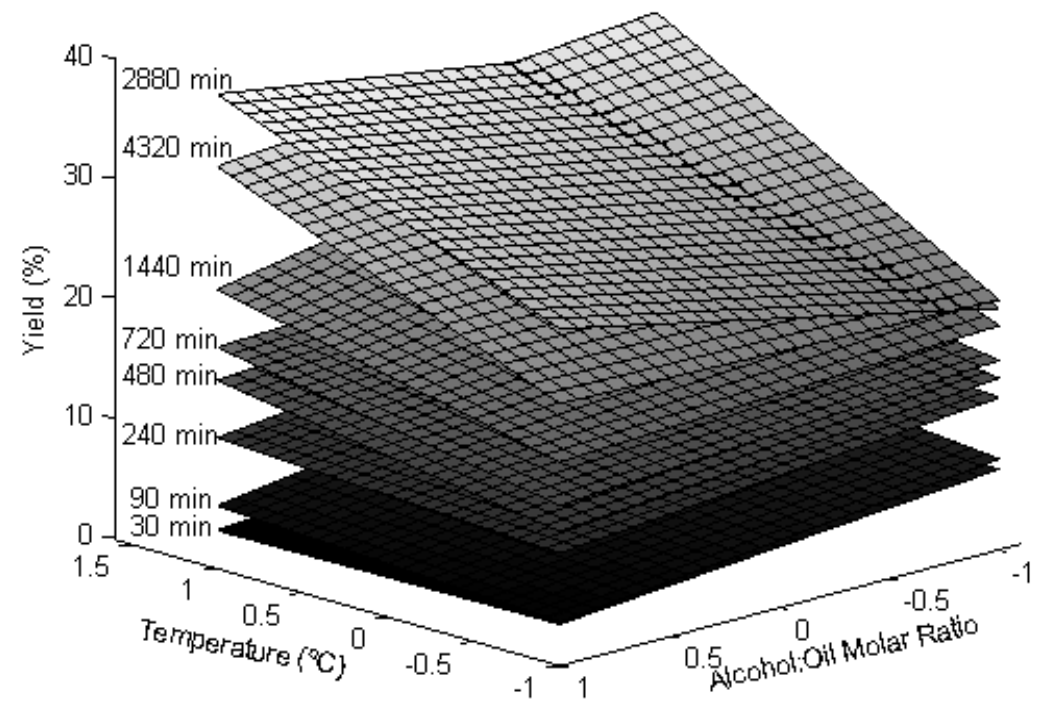

Fig 3: Response surface of the experimental design for the coded variables in function of the time.

Despite being widely used, these models have some limitations. An important limitation is the use of a second-order equation to describe these processes, since a model with this type of equation cannot cover all variations of a process [1].

The fitting equations shown in Table 3 that constitute the models derived from the results of a multifactorial design of experiments using the non-significant variables were represented by response surfaces as a function of time in Figure 3. The dynamic of the variables which influence the ester production process can be verified by the change in slope and curvature of these surfaces.

Figure 3a displays the ester yield as a function of temperature and amount of enzyme, showing the shape of the response surfaces changes little during the course of reaction, i.e. there is a single setting of conditions of reaction medium that provides the maximum production yield under the conditions studied. Moreover, Figures $3 \mathrm{~b}$ and $3 \mathrm{c}$ show that some response surfaces intersect, indicating that the higher yield condition is different depending on the reaction time. Then, the dynamic control of the reaction variables, always seeking the highest yield for each reaction time, should provide an increase in the overall rate of reaction. This gain in reaction rate due to correct and optimized handling of variables allows the yield reached at $4320 \mathrm{~min}$ in absence of dynamic control to be obtained at $2880 \mathrm{~min}$.

\subsection{Ester production using dynamic manipulation of process variables}

Indeed, by manipulating variables as described in Table 2, the reaction yield observed was higher than when the variables were kept unchanged throughout the reaction period. Furthermore, as shown in Figure 4, the reaction was faster, since higher yields $(80,1 \%)$ were reached at lower reaction times and higher enzymatic activity of ester production, $5577.18 \mathrm{U} / \mathrm{g}$ of protein. Thereby, the static reactor operation was less efficient than the dynamic operation.

The high efficiency found may be caused by a transient optimization of reaction conditions in periods in which the variables, combined or alone, have more influence on the increase of reaction yield and enzymatic ester activity.

Table 2: Conditions of reactor operation using non-static variables

\begin{tabular}{|c|c|c|c|c|c|c|c|c|c|c|c|c|c|}
\hline \multirow{2}{*}{ Variables } & \multicolumn{13}{|c|}{ Time reaction (min) } \\
\hline & 0 & 30 & 60 & 90 & 120 & 240 & 360 & 480 & 600 & 720 & 1440 & 2880 & 4320 \\
\hline Temperture (으) & 30 & 30 & 32 & 33 & 33 & 36 & 41 & 44 & 44 & 44 & 51 & 60 & 60 \\
\hline Molar ratio (alcoohol/Oil) & 1:1 & 1:1 & 1:1 & 1:1 & $3: 1$ & 3:1 & $3: 1$ & 4:1 & $5: 1$ & $5: 1$ & 9:1 & $12: 1$ & $12: 1$ \\
\hline Amount of Enzyme (\%) & 5 & 5 & 6 & 6 & 7 & 7 & 7 & 7 & 7 & 7 & 8 & 10 & 10 \\
\hline
\end{tabular}

This transient operation of variables is necessary because characteristics of the medium vary as the reaction evolves. In the ester production, for example, changes in the polarity, solubility and viscosity of the reaction medium are observed. Thus, the operation conditions must change too in these periods so that enzymes can take new conformation more compatible with these new features. In the specific case of enzymatic lipases reactions, polarity is a limiting factor, because it directly influences the phenomenon of interfacial activation of the active site. 


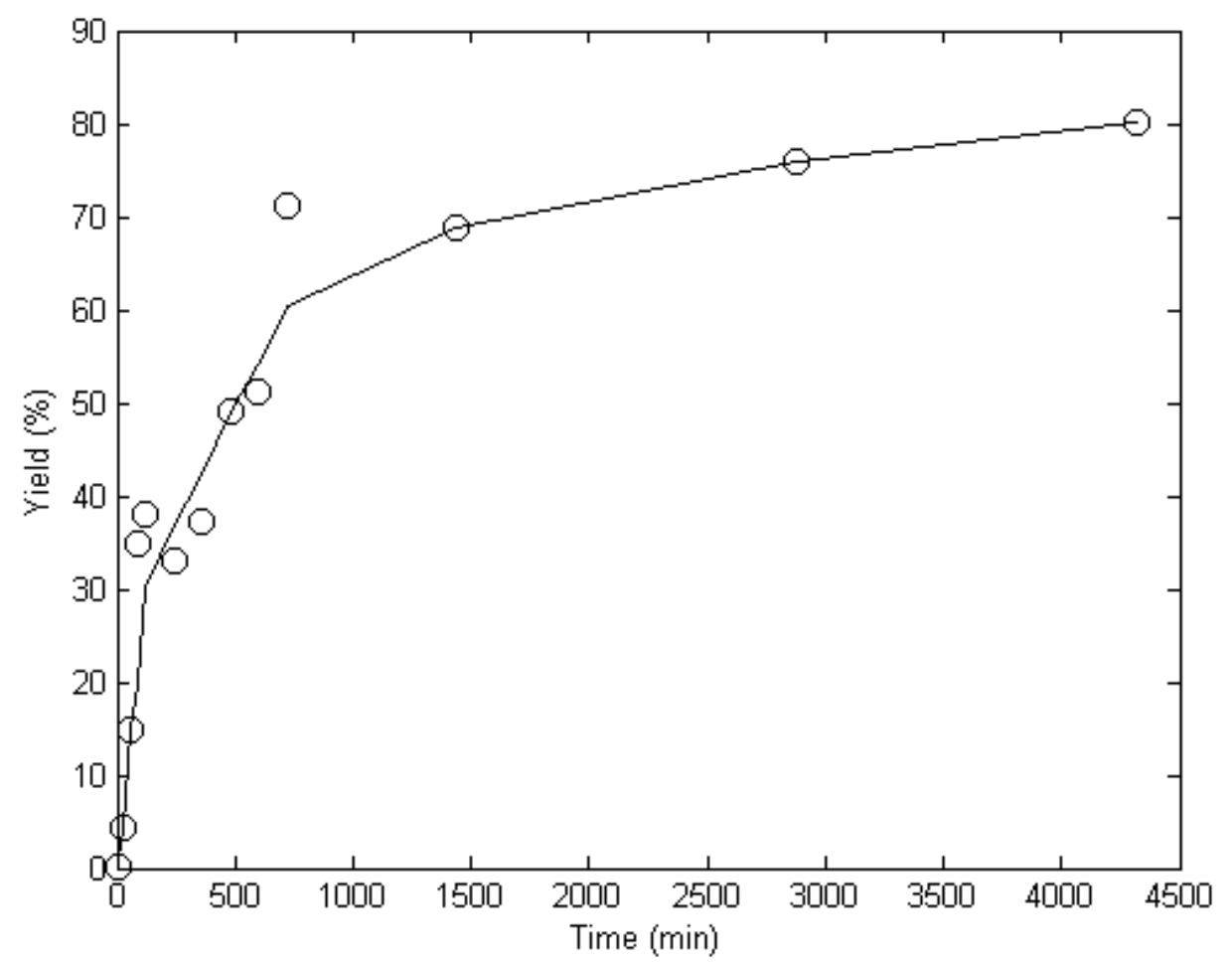

Fig 4: Ester production using non-static variables condition of reactor

Finding the best conditions of manipulation of variables in function of time is complicated, given the number of possible combinations. However, a factorial design analyzed at different times can assist in this regard, since it demonstrates which variable was most important in each period. Of course some conditions are not applicable, such as removal of the enzyme reaction medium or alcohol extraction in the middle of the reaction development. But this is outweighed by an interpretation of the data by the experimentalist. The condition used to operate the reactor may not be yet the best possibility since the maximum yield achieved was $80.1 \%$. Also, the manipulation of another variable, not contemplated in this work, can achieve a higher yield.

\section{CONCLUSION}

A standard estimation of the effects was studied in the production of radish oil ethyl ester, using Burkholderia cepacia lipase, as a function of time, and it was possible to analyze and describe the importance of each variable features throughout the reaction. Even though the phenomena is related to multiple variables and their complex interactions, we were able to determine which variable and in what period of reaction each of them is influencing ester production and to what extent. The reviewed previous studies conclude that all studied variables are important to the system even though their influence trends show divergent behaviors between works. We agree with the importance of the variables but having determined their effects as a function of time, we propose dynamic time control of variables for reaching higher ester production. For temperature, it is suggested the lipase should be subjected to temperatures of maximum activity in a shorter time, close to the end of the reaction, the moment when it most strongly influences the yield and the thermal inactivation effects would be smaller. The fractional addition of alcohol was not sufficient to prevent its adverse effects to the reaction, so a constant addition of alcohol proportional to the consumption of reagents could be a better solution. The effects of mass transfer resistance related to greater amounts of lipase were analyzed and judged a not significant factor in the yield of reaction. Even with the limitation of the models, it was possible to analyze the behavior of the reaction medium and to propose situations where higher yields were obtained.

In fact, when the reactor was operated dynamically, following the planning information, an $80,1 \%$ yield was achieved. When statically operated, the reaction yield was $39.9 \%$ taking a longer time for this value to be achieved. Also, enzymatic activity of ester production was $5577.18 \mathrm{U} / \mathrm{g}$ protein, much higher than those found under static condition in which the highest was $48.19 \mathrm{U} / \mathrm{g}$ of protein.

\section{ACKNOWLEDGMENTS}

The authors thank the Chemical Engineering Department of the State University of Maringá for the support and CAPES for funding the research project (Pró-engenharias 23038-028317/2008-44) and Kety . 


\section{REFERENCES}

[1] D. Baş, İ.H. Boyacı, "Modeling and optimization II: Comparison of estimation capabilities of response surface methodology with artificial neural networks in a biochemical reaction", Journal of Food Engineering. 2007, 78:846-54.

[2] M. Farooq Anjum, I. Tasadduq, K. Al-Sultan, "Response surface methodology: A neural network approach". European Journal of Operational Research. 1997, 101:65-73.

[3] N.R. Draper, "Response surface methodology: Process and product optimization using designed experiments". Journal of Statistical Planning and Inference. 1997, 59:185-6.

[4] A.L. Ahmad, P.C. Oh, S.R. Abd Shukor, "Synthesis of 2-oxo-4-phenylbutanoic acid: Parameter optimization using response surface methodology". Chemical Engineering Journal. 2011;171:640-5.

[5] Y. Liu, D. Chen, Y .Yan, C. Peng, L. Xu, "Biodiesel synthesis and conformation of lipase from Burkholderia cepacia in room temperature ionic liquids and organic solvents". Bioresource Technology 2011;102:10414-8.

[6] C.H. Kuo, F.W. Hsiao, J.H. Chen, C.W. Hsieh, Y.C. Liu, C.J. Shieh, "Kinetic aspects of ultrasound-accelerated lipase catalyzed acetylation and optimal synthesis of 4'-acetoxyresveratrol”. Ultrasonics Sonochemistry. 2013; 20:546-52.

[7] C.H. Kuo, S.H. Chiang, H.Y. Ju, Y.M. Chen, M.Y. Liao, Y.C. Liu, C.J. Shieh. "Enzymatic synthesis of rose aromatic ester (2-phenylethyl acetate) by lipase. Journal of the Science of Food and Agriculture. 2012;92:2141-7.

[8] N.S. Neta, A.M. Peres, J.A. Teixeira, L.R. Rodrigues. "Maximization of fructose esters synthesis by response surface methodology". New Biotechnology. 2011;28:349-55.

[9] H.Y. Shin, S.M. Lim, S.C. Kang, S.Y. Bae. "Statistical optimization for biodiesel production from rapeseed oil via transesterificaion in supercritical methanol". Fuel Processing Technology. 2012;98:1-5.

[10] Z. Findrik, G. Németh, L. Gubicza, K. Bélafi-Bakó, Đ. Vasić-Rački. "Evaluation of factors influencing the enantioselective enzymatic esterification of lactic acid in ionic liquid". Bioprocess and Biosystems Engineering. 2012;35:625-35.

[11] C. Delgado, V. Pashova. "Enzymatic production of ethyl esters from castor oil". Revista Facultad de Ingeniería Universidad de Antioquia. 2010;9-19.

[12] S.P. De Souza, L.L.S. Pereira, A.A. Souza, C.D. dos Santos. "Inhibition of pancreatic lipase by extracts of Baccharis trimera: evaluation of antinutrients and effect on glycosidases". Revista Brasileira de Farmacognosia. 2011;21:450-5.

[13] M.I. Rodrigues, P.R.A. Costa. 2009. Planejamento de experimentos e otimização de processos. 2nd ed. Lemma AF, editor. Campinas, S.P. - Casa do Espírito Amigo Fraternidade Fé e Amor;. 356 p.

[14] K. Nie, F. Xie, F. Wang, T. Tan. "Lipase catalyzed methanolysis to produce biodiesel: Optimization of the biodiesel production”. Journal of Molecular Catalysis B: Enzymatic. 2006;43:142-7.

[15] J.B. Kristensen, X. Xu, H. Mu. "Process optimization using response surface design and pilot plant production of dietary diacylglycerols by lipase-catalyzed glycerolysis”. Journal Agricultural Food Chemistry. 2005;53:7059-66.

[16] N. Paroul, L. Grzegozeski, V. Chiaradia, H. Treichel, R. Cansian, J.V. Oliveira, J. V. Oliveira, D. Oliveira. "Solvent-free geranyl oleate production by enzymatic esterification". Bioprocess and Biosystems Engineering. 2011;34:323-9.

[17] C. Verdugo, D. Luna, A. Posadillo, E.D. Sancho, S. Rodríguez, F. Bautista, R. Luque, J. M. Marinas, A. A. Romero. "Production of a new second generation biodiesel with a low cost lipase derived from Thermomyces lanuginosus: Optimization by response surface methodology". Catalysis Today. 2011;167:107-12.

[18] M.H.M. Avelar, D.M.J. Cassimiro, K.C. Santos, R.C.C. Domingues, H.F. Castro, A.A. Mendes. "Hydrolysis of vegetable oils catalyzed by lipase extract powder from dormant castor bean seeds". Industrial Crops and Products. 2012;44: 452-458.

[19] B. Chen, W. Huang. "Effects of compositional heterogeneity and nanoporosity of raw and treated biomass-generated soot on adsorption and absorption of organic contaminants". Environmental Pollution. 2011;159:550-6.

[20] M.P. Bousquet-Dubouch, M. Graber, N. Sousa, S. Lamare, M. D. Legoy. "Alcoholysis catalyzed by Candida antarctica lipase $\mathrm{B}$ in a gas/solid system obeys a Ping Pong Bi Bi mechanism with competitive inhibition by the alcohol substrate and water". Biochimica et Biophysica Acta (BBA) - Protein Structure and Molecular Enzymology. 2001;1550:90-9.

[21] D. Royon, M. Daz, G. Ellenrieder, S. Locatelli. "Enzymatic production of biodiesel from cotton seed oil using t-butanol as a solvent". Bioresource Technology. 2007;98:648-53.

[22] C. Sun, S. Gunasekaran. "Effects of protein concentration and oil-phase volume fraction on the stability and rheology of menhaden oil-in-water emulsions stabilized by whey protein isolate with xanthan gum". Food Hydrocolloids. 2009;23:165-74.

[23] H. Chen, C.H. Kuo, H. Chen, Y.C. Liu, C. Shieh. "Optimization of Enzymatic Synthesis of Cetyl 2-Ethylhexanoate by Novozym® 435”. Journal of the American Oil Chemists' Society. 2011;88:1917-23. 
[24] J. Xin, L. Chen, Y. Zhang, S. Zhang, C. Xia. "Lipase-catalyzed transesterification of ethyl ferulate with triolein in solvent-free medium". Food and Bioproducts Processing. 2011;89:457-62.

[25] A. Coteron, M. Martinez, J. Aracil. "Reactions of olive oil and glycerol over immobilized lipases". Journal of the American Oil Chemists' Society. 1998;75:657-60.

[26] J.Q. Li, Y.D. Huang, S.Y. Fu, L.H. Yang, H. Qu, G. Wu. "Study on the surface performance of carbon fibres irradiated by $Y$-ray under different irradiation dose". Applied Surface Science. 2010;256:2000-4.

[27] D. Yu, L. Tian, H. Wu, S. Wang, Y. Wang, D. Ma, X. "Fang. Ultrasonic irradiation with vibration for biodiesel production from soybean oil by Novozym 435". Process Biochemistry. 2010;45:519-25.

[28] D.M.F. Prazeres, F.A.P. Garcia, J.M.S. Cabral. "Batch and continuous lipolysis/product separation in a reversed micellar membrane bioreactor". Progress in Biotechnology. 1992;8:713-8.

[29] L.M.O. Ribeiro, B.C.S. Santos, R.M.R.G. Almeida. "Studies on reaction parameters influence on ethanolic production of coconut oil biodiesel using immobilized lipase as a catalyst". Biomass and Bioenergy. 2012;47:498-503.

[30] J.H. Dantas, L.D. Paris, C.E. Barão, P.A. Arroyo, C.M.F. Soares, J.V. Visentainer, F. Faria and G. M. Zanin. "Influence of alcohol: oil molar ratio on the production of ethyl esters by enzymatic transesterification of canola oil". African Journal of Biotechnology. 2013;12:12.

[31] M. Holčapek, P. Jandera, P. Zderadička, L. Hrubá. "Characterization of triacylglycerol and diacylglycerol composition of plant oils using high-performance liquid chromatography-atmospheric pressure chemical ionization mass spectrometry". Journal of Chromatography A. 2003;1010:195-215.

[32] D.M. Cetina, G.I. Giraldo, C.E. Orrego. "Application of response surface design to solvent, temperature and lipase selection for optimal monoglyceride production”. Journal of Molecular Catalysis B: Enzymatic. 2011;72:13-9.

[33] R. Dalla-Vecchia, M. G. Nascimento, V. Soldi. “Aplicações sintéticas de lipases imobilizadas em polímeros”. Quimica Nova. 2004;27:623-30.

[34] A. Converti, A. Del Borghi, R. Gandolfi, F. Molinari, E. Palazzi, P. Perego, M. Zillia. " Simplified kinetics and thermodynamics of geraniol acetylation by lyophilized cells of Aspergillus oryzae”. Enzyme and Microbial Technology. 2002;30:216-23.

[35] M. Karra-Châabouni, H. Ghamgui, S. Bezzine, A. Rekik, Y. Gargouri. "Production of flavour esters by immobilized Staphylococcus simulans lipase in a solvent-free system". Process Biochemistry. 2006;41:1692-8.

[36] K.E. Jaeger, T. Eggert. "Lipases for biotechnology". Current Opinion in Biotechnology. 2002;13:390-7.

[37] X. Fu, X. Zhu, K. Gao, J. Duan. "Oil and fat hydrolysis with lipase from Aspergillus sp." Journal of the American Oil Chemists' Society. 1995;72:527-31.

[38] O'Fagain, C. 2004 Storage of Pure Proteins. In. Methods in molecular biology. New York: Humam Press Ltd. 